SCIREA Journal of Clinical Medicine

ISSN: 2706-8870

http://www.scirea.org/journal/CM

November 30, 2021

Volume 6, Issue 6, December 2021

https://doi.org/10.54647/cm32666

\title{
Study of wrist, finger and crystalline dosimetry in radiopharmacists and nursing assistants to adjust a percentage factor between the extremities
}

\author{
M. I. C. C. Guimarães ${ }^{1}$, I. B. Melo ${ }^{1}$, E. N. Itikawa ${ }^{2}$, U. F. de Souza ${ }^{1}$, C. A. Buchpiguel ${ }^{1}$, \\ H. S. Videira ${ }^{1}$ \\ ${ }^{1}$ Universidade de São Paulo, Centro de Medicina Nuclear do Instituto de Radiologia do \\ Hospital das Clínicas da Faculdade de Medicina \\ ${ }^{2}$ Universidade Federal de Goiás \\ Email: micguima@usp.br (M. I. C.C. Guimarães), ivani.melo@hc.fm.usp.br (I.B. Melo), \\ emersonitikawa@ufg.br (E. N. Itikawa),uysha.fonda@hc.fm.usp.br (U. F. de Souza), \\ buch@usp.br (C. A. Buchpiguel), videira@hc.fm.usp.br (H. S. Videira)
}

\begin{abstract}
:
This work finds a correlation factor setting a percentage of the difference between the values obtained at the body extremities. The data was obtained from 4 workers who inject and dispose radiopharmaceuticals. The workers handling radioactive material worn both ring and wrist dosimeters, with the exception of the radiopharmacist who worn one dosimeter on each wrist and a ring on his right hand. The dosimeters were TLD. To measure the crystalline, dosimeters were placed in each rod of workers' safety goggles. The results show that for the radioisotope 99m Tc were carried out a total of 20 elutions; 49 markings and 199 fractioning. Fourteen fractioning to ${ }^{18} \mathrm{~F}, 4{ }^{131} \mathrm{I},{ }^{67} \mathrm{Ga}$ with 3 and 1 to ${ }^{111} \mathrm{In}$. The radiopharmacist's ring showed dose of $11 \mathrm{mSv}$, while the wrist dosimeter marked $7.78 \mathrm{mSv}$ on the right and $5.40 \mathrm{mSv}$ on the left. The
\end{abstract}


goggles showed $0.43 \mathrm{mSv}$ on the left side and $0.52 \mathrm{mSv}$ on right side. The nurse's results were: Nurse A: $1.13 \mathrm{mSv}$ in ring and 0.23 in wrist; Nurse B: $1.11 \mathrm{mSv}$ in ring and $0.90 \mathrm{mSv}$ in wrist; Nurse C: $0.73 \mathrm{mSv}$ in ring and $0.56 \mathrm{mSv}$ in wrist. The goggles worn by Nurse B recorded 0.19 $\mathrm{mSv}$ on the right side and $\mathrm{BG}$ on the left side. The difference between the dose received by wrists and rings was between $20 \%$ and $30 \%$. This factor obtained in these data encourages continuing research and shows that wrist dosimetry is feasible, respecting the proportionality.

Keywords: Dosimetry, OEI, Crystalline, Wrist, Fingers.

\section{INTRODUCTION}

For workers in Nuclear Medicine, especially radiopharmacists and nursing technicians who apply medication to patients, the doses they receive in the extremities is a factor of concern. Although the annual equivalent dose limit for these regions is high (500 mSv /year), these doses have to be controlled and linked to good work practices 1 .

Currently in Brazil there are 11 laboratories certified to provide external individual monitoring services, but not all of them offer finger dosimetry. This type of dosimetry is also not well accepted by most workers, who claim to experience great difficulty in adapting to the ring while wearing the gloves. In addition, many fear forgetting to remove it before disposing the gloves, throwing it in the garbage or contaminating it.

Wrist dosimetry is an alternative, but many radioprotection organizations, find that this evaluation not sufficient to verify the dose in the final extremities. Those competent studies report potential difference between the equivalent dose received by the worker in fingers when used wrist dosimeters.

In this scenario, this work was developed to improve the quality of the dosimetry implemented in nuclear medicine services and to obtain a percentage difference between these measurements. The study's goal is to obtain the dosimetry of the extremities (fingers and wrists), and of the crystalline of workers, who inject and dispose, mark and distribute radiopharmaceuticals. Those observations may allow finding a correlation factor that adjusts a percentage between the differences measured in these extremities. With these data, it may be possible to choose between the use of ring dosimetry or the wrist dosimetry continuity. 
The knowledge of the percentage of this difference will allow optimizing the dosimetry and thus improve the quality of dosimetric measurements in the services.

\section{METHODS}

Four workers who directly handle with radioactive material participated in this study, which had duration of one month. Three nursing assistants worn one ring and one wrist type dosimeters; the radiopharmacist worn a dosimeter on each wrist and a ring type one on his right hand. The dosimeters were TLD and have been adapted for use on finger. Since the workers are Occupationally Exposed Individuals (OEI's), they also used the TLD chest dosimeter, in addition to the extremities ones. Nevertheless, the chest dosimeter was not accounted in this study. Two workers were wearing safety goggles: the radiopharmacist and one nursing assistant. On both safety goggles, a dosimeter in each rod was installed in order to measure the radiation that can reach the crystalline.

The radionuclides used in the period were: ${ }^{99 \mathrm{~m}} \mathrm{Tc},{ }^{67} \mathrm{Ga},{ }^{18} \mathrm{~F},{ }^{131} \mathrm{I}$ and ${ }^{111} \mathrm{I}$.

\section{RESULTS}

The radiopharmacist accounted for a total of 20 elutions, in relation to the ${ }^{99 \mathrm{~m}} \mathrm{Tc}$ radioisotope $(504,384 \mathrm{MBq}$ or $13,632 \mathrm{mCi}) ; 49$ markings $(258,075 \mathrm{MBq}$ or $6,975 \mathrm{mCi})$ and 199 fractionations $(143,346.51 \mathrm{MBq})$. Fourteen fractionations were performed for the ${ }^{18} \mathrm{~F}$ radioisotope $\left(3,774.74 \mathrm{MBq}\right.$ or $105.02 \mathrm{mCi}$;), 4 procedures with ${ }^{131} \mathrm{I}(266.4 \mathrm{MBq}$ or $7.2 \mathrm{mCi})$, 3 fractionations of the ${ }^{67} \mathrm{Ga}$ radioisotope $(886.89 \mathrm{MBq}$ or $23,97 \mathrm{mCi})$ and 1 for ${ }^{111} \mathrm{In}(185$ $\mathrm{MBq}$ or $5 \mathrm{mCi}$ ). The ring dosimeter used by the worker had a dose of $11 \mathrm{mSv}$, while the wrist on the right had a dose of $7.78 \mathrm{mSv}$ and the one on the left, $5.40 \mathrm{mSv}$. The radiopharmacist is right-handed. The safety goggles presented a dose of $0.43 \mathrm{mSv}$ on the left side and $0.52 \mathrm{mSv}$ on the right side. The recorded time of work performed by the professional was between 30 seconds in the removal of the material and 1 minute in the elutions.

The nursing assistants, for the same amounts of activity, except for marking and elutions, presented the following results: Nurse A: $1.13 \mathrm{mSv}$ in the ring and 0.23 in the wrist; Nurse B: $1.11 \mathrm{mSv}$ ring and $0.90 \mathrm{mSv}$ wrist; Nurse $\mathrm{C}: 0.73 \mathrm{mSv}$ on the ring and $0.56 \mathrm{mSv}$ on the wrist. The safety goggles were worn only by Nurse B and recorded $0.19 \mathrm{mSv}$ on the right 
side and BG on the left side. The distance between the position of the OEI eyes and the radioactive material to be applied to the patient's arm was approximately between 30 and 40 $\mathrm{cm}$. The application duration was of approximately 1 minute.

Table 1: Doses obtained for wrist, ring and crystalline measured during one month, for Occupationally Exposed Individuals (OEI's) in Nuclear Medicine

\begin{tabular}{lccccc}
\hline OEI & $\begin{array}{c}\text { RIGHT } \\
\text { WRIST } \\
(\mathbf{m S v})\end{array}$ & $\begin{array}{c}\text { LEFT } \\
\text { WRIST } \\
(\mathbf{m S v})\end{array}$ & $\begin{array}{c}\text { RING } \\
(\mathbf{m S v})\end{array}$ & $\begin{array}{c}\text { GOGGLES } \\
\text { RIGHT } \\
(\mathbf{m S v})\end{array}$ & $\begin{array}{c}\text { GOGGLES } \\
\text { LEFT } \\
(\mathbf{m S v})\end{array}$ \\
\hline RADIOPHARMACIST & 7,78 & 5,40 & 11 & 0,52 & 0,43 \\
NURSE A & 0,23 & - & 1,13 & - & - \\
NURSE B & 0,90 & - & 1,11 & 0,19 & BG \\
NURSE C & 0,56 & - & 0,73 & - & - \\
\hline
\end{tabular}

The measured difference between the doses received by workers on wrists and rings was between $20 \%$ and $30 \%$. This already shows a good pattern for using wrist dosimetry using this correction factor.

The dosimetry of crystalline remained low and without problems with the dose limit adopted in Brazil, which is $20 \mathrm{mSv} / \mathrm{year}$ [Standart CNEN-NN-3.05, 2013, Standart CNEN-3.01, 2014].

\section{CONCLUSION}

The data show that there is a good technical efficiency of workers [EUROPEAN COMMISSION, 2013]. The doses obtained are within the standards established by the standards in place in Brazil and by the recommendations presented by the radioprotection organizations worldwide.

To have a reliable factor between wrist and finger dosimetry facilitates the optimization of this dosimetry. This will help workers and services that find it difficult to adopt ring type dosimeters to have greater control over their exposures.

It is essential that there is good dosimetry in the service to guarantee the safety and reliability of the OEI's in their Radiation Protection supervisors and immediate superiors. This way, they can convey calm and tranquility to the patients.

\section{ACKNOWLEDGMENT}


The authors are grateful for the participation of occupationally exposed individuals from the Nuclear Medicine service, who collaborated with the development of the work.

\section{REFERENCES}

[1] European Commission - Joint Research Centre, Ispra, Italy, Teófilo Moltó Caracena, João MG Gonçalves, Paolo Peerani, Eduardo Vendrell. Virtual Reality Based Accurate Radioactive Source Representation And Dosimetry For Training Applications, 2013.

[2] IAEA- Safety Standards Series Assessment of Occupational Exposure Due to External Sources of Radiation Jointly Sponsored By The International Atomic Energy Agency and The International Labor Office Safety Guide No. RS-G-1.3 (1999).

[3] International Commission on Radiological Protection. ICRP Publication 103. Recommendations of the ICRP. Annals of the ICRP, vol. 27/2-4. Elsevier; 2008.

[4] International Commission on Radiological Protection. Recommendations of the International Commission on Radiological Protection. ICRP Publication 60 (Oxford Pergamon) (1990).

[5] Standard CNEN-NN 3.05 - Safety and Radiological Protection Requirements for Nuclear Medicine Services (CNEN Resolution 159/13). December 2013.

[6] Standard CNEN-NN 3.01 - Basic Radiological Protection Guidelines. Resolution 164/14.March 2014. 